\title{
PENERAPAN RASIO SAMPLING DALAM PENDUGAAN RASIO LAHAN KRITIS DI WILAYAH DAS JRATUN
}

\author{
Iwa Sungkawa \\ Mathematics \& Statistics Department, School of Computer Science, Binus University \\ Jln. K.H. Syahdan no. 9, Palmerah, Jakarta Barat 11480 \\ iwasungkawa@yahoo.com
}

\begin{abstract}
This study aims to examine the application of ratio estimators on a sampling method by taking the case of estimating the ratio of critical land of every county around Jratun watershed. Through the estimation, a general description of critical land deployment for each region (county) can be obtained. In addition, the estimator of hose/interval is also determined for the ratio with the real level of 0.05. The simple random sampling method is used in conducting the estimation of ratio of the critical land to the total land area. The estimation results show that the ratio of the critical land to the total area for 19 districts reaches $23.72 \%$.
\end{abstract}

Keywords: ratio estimation, critical land, watershed

\begin{abstract}
ABSTRAK
Penelitian ini bertujuan untuk menelaah penerapan penduga rasio dalam metode penarikan sampel dengan mengambil kasus pendugaan rasio lahan kritis setiap kabupaten di daerah aliran sungai (DAS) jratun. Melalui pendugaan ini dapat diperoleh gambaran atau keragaan penyebaran lahan kritis untuk setiap wilayah (kabupaten). Di samping itu ditentukan juga penduga selang/interval untuk rasio tersebut dengan taraf nyata 0,05. Metode penarikan sampel acak sederhana digunakan dalam melakukan pendugaan rasio lahan kritis terhadap total luas wilayah. Hasil pendugaan menunjukan bahwa rasio lahan kritis terhadap total luas wilayah untuk 19 kabupaten mencapai 23.72\%.
\end{abstract}

Kata kunci: penduga rasio, lahan kritis, daerah aliran sungai 


\section{PENDAHULUAN}

Lahan kritis adalah lahan yang keadaan fisiknya sedemikian rupa sehingga lahan tersebut tidak dapat berfungsi secara baik sesuai dengan peruntukkannya sebagai media produksi pertanian maupun sebagai media tata guna air (BPDAS Pemali Jratun, 2010). Lahan kosong/gundul dan tidak produktif dapat dianggap sebagai lahan kritis atau lahan marginal.

Beberapa penyebab terjadinya lahan kritis adalah perambahan hutan, penebangan liar (illegal logging), kebakaran hutan, pemanfaatan sumber daya hutan yang tidak berazaskan kelestarian, penataan zonasi kawasan belum berjalan, pola pengelolaan lahan tidak konservatif, dan pengalihan status lahan (berbagai kepentingan) (BPDAS Pemali Jratun, 2010).

Akibatnya: (1) daya resap tanah terhadap air menurun sehingga kandungan air tanah berkurang yang mengakibatkan kekeringan pada waktu musim kemarau; (2) terjadinya arus permukaan tanah pada waktu musim hujan yang mengakibatkan bahaya banjir dan longsor; (3) menurunnya kesuburan tanah, dan daya dukung lahan serta keanekaragaman hayati. Apabila kondisi tersebut dibiarkan terus berlangsung, pada akhirnya akan menyebabkan produktifitas lahan dan produksi pertanian menurun sehingga pada akhirnya akan menyebabkan kemiskinan masyarakat, khususnya masyarakat tani.

Lahan kritis merupakan salah satu faktor yang penting dalam penanggulangan kerusakan DAS, yang luasnya semakin bertambah setiap tahun. Meningkatnya kerusakan lahan dapat berpengaruh negatif terhadap perkembangan produksi dan ketersediaan pangan di setiap wilayah atau Kabupaten, dan menipisnya ketersediaan pangan akan menimbulkan berbagai masalah yang terjadi di masyarakat.

Menyimpulkan kondisi populasi dari suatu penelitian, dalam hal ini kondisi lahan kritis, dapat dilakukan dengan menarik sampel dari populasi tersebut. Sampel yang diambil harus mewakili populasi secara keseluruhan. Ukuran-ukuran populasi yang disebut parameter diduga oleh statistika yang merupakan ukuran dari sampel. Dalam statistika dikenal berbagai ukuran yang di antaranya adalah rata-rata, ragam dan simpangan baku, koefisien korelasi serta proporsi dan rasio. Upaya untuk memperkirakan nilai dari parameter dengan statistik disebut pendugaan (estimation). Dalam kesempatan ini akan dibahas bagaimana menduga nilai rasio (nisbah) dari suatu karakteristik.

Pendugaan rasio ditempuh dengan melalui pengukuran suatu peubah sebut saja $y$ dan satu atau lebih peubah tambahan $(X)$ yang berkorelasi erat dengan peubah tersebut. Metode pendugaan ini membutuhkan pengukuran dari dua peubah $y$ dan $x$ pada setiap unit dari sampel dan dapat digunakan berbagai jenis teknik penarikan sampel. Dalam suatu survai yang bertujuan untuk menduga nilai total populasi tetapi ukuran populasi itu tidak diketahui secara pasti dapat digunakan peduga rasio sebagai dasar untuk menentukan nilai dugaannya.

Untuk memberikan gambaran yang lebih jelas tentang penggunaan penduga rasio dalam sampling, berikut diberikan kajian dalam melakukan pendugaan rasio luas lahan kritis terhadap total luas keseluruhan dari wilayah yang diamati. Kegiatan penelitian dilaksanakan di wilayah/daerah aliran sungai (DAS) Jratun yang terdiri dari 19 kabupaten. Untuk menduga rasio tersebut digunakan metode penarikan sampel acak sederhana.

Dalam penelitian kita berusaha untuk menyimpulkan populasi di mana sampel diambil untuk mewakili populasi tersebut. Untuk tujuan tersebut kita mencari atau mempelajari data yang diambil baik secara sampling maupun sensus. Karena keterbatasan waktu, dana serta mengingat besarnya populasi (tak hingga), diambil sampel yang representatif. Lalu berdasarkan hasil analisis terhadap data 
sampel, kesimpulan mengenai populasi dibuat. Kelakuan populasi yang akan ditinjau disini hanyalah mengenai parameter populasi dan sampel yang digunakan adalah sampel acak. Data dari sampel dianalisis diperoleh nilai-nilai statistik atau statistik sampel. Statistik sampel yang diperoleh digunakan untuk menduga parameter-parameter dari populasi.

Secara umum parameter populasi diberi simbul $\theta$ (baca theta) jadi $\theta$ bisa berupa rata-rata $\mu$ simpangan baku $\alpha$, proporsi $\mathrm{P}$ dan sebagainya. Jika $\theta$ yang tidak diketahui harganya diduga oleh $\theta^{\prime}$ maka $\theta^{\prime}$ dinamakan penduga titik jelas diinginkan $\theta^{\prime}=\theta$ tetapi ini hanya merupakan suatu keinginan yang ideal sifatnya, kenyataan yang terjadi adalah: (1) penduga $\theta$ oleh $\theta^{\prime}$ terlalu tinggi; (2) penduga $\theta$ oleh $\theta^{\prime}$ terlalu rendah (Douglas \& William, 1990).

Kedua hal ini jelas tidak diinginkan oleh peneliti karena kami menginginkan penduga yang baik penduga yang baik adalah tak bias, mempunyai varians (ragam) minimum dan konsisten. Penduga $\theta^{\prime}$ dikatakan penduga tidak bias jika rata-rata semua harga $\theta^{\prime}$ yang mungkin akan sama dengan $\theta$. Penduga beragam minimum ialah penduga dengan ragam terkecil di antara semua penduga untuk parameter yang sama. Jika $\theta_{1}^{\prime}$ dan $\theta_{2}^{\prime}$ dua penduga beragam minimum dan merupakan penduga yang baik. Misalkan $\theta^{\prime}$ penduga untuk $\theta$ yang dihitung berdasarkan sampel acak berukuran $n$. jika ukuran sampel $n$ makin besar mendekati ukuran populasi, akan menyebabkan $\theta^{\prime}$ mendekati $\theta$, sehingga $\theta^{\prime}$ dijamin merupakan penduga konsisten. Penduga yang tak bias dan beragam minimum dinamakan penduga yang baik.

Orang sering merasa kurang yakin atau kurang percaya atas hasil penduga titik ini. Untuk lebih meyakinkan, dilakukan pendugaan interval/selang atau daerah pendugaan yaitu menduga suatu parameter di antara batas-batas dua harga dengan tingkat kepercayaa yang telah ditentukan (Vincent, 1989).

Jika koefisien kepercayaan dinyatakan dengan $\partial$, besarnya $0<\partial<1$. harga $\partial$ yang digunakan tergantung pada persoalan yang dihadapi dan keyakinan peneliti. namun yang biasa digunakan ialah $0.90 ; 0.95$ atau 0.99 . Jadi pendugaan $\theta$ yang dimaksud adalah:

$$
\mathrm{P}(\mathrm{A}<\theta<\mathrm{B})=\partial
$$

di mana P: peluang yang diiginkan; A: batas bawah pendugaan; B:batas atas pendugaan; $\theta$ : parameter yang diduga; $\partial$ : koefisien kepercayaan pendugaan. Peluang $\theta$ terletak di antara nilai A dan B sebesar $\partial$. Dalam penelitian A dan B dihitung harganya berdasarkan data sampel.

Artikel ini menyajikan kriteria lahan kritis, kondisi dan upaya penanganan dengan tujuan mendapatkan informasi sebagai bahan dalam pengambilan kebijakan dalam menanggulangi lahan kritis agar dapat di atasi dan dimanfaatkan. Dengan informasi ini institusi atau pejabat yang kompeten dapat dengan mudah menyusun strategi untuk mengatasi dan mengantisipasi/mencegah akibat dari adanya lahan kritis tersebut, seperti bencana banjir, longsor dan kekeringan.

\section{METODE}

\section{Bahan}

Dalam penulisan artikel ini digunakan data sekunder yang bersumber dari internet dan merupakan hasil pelaksanaan kegiatan penyusunan/review data spasial lahan kritis tahun 2009 wilayah BPDAS Pemali Jratun. Data lahan kritis tersebut dapat disajikan untuk 19 Kabupaten sekitar DAS Jratun, yang meliputi Kabupaten: Brebes, Tegal dan Kota Tegal, Pemalang, Pekalongan dan Kota Pekalongan, Batang, Kendal, Semarang dan Kota Semarang, Demak, Kudus, Jepara, Pati, Rembang, Blora, Grobogan, Boyolali dan Kota Salatiga. Total luas wilayah untuk 19 kabupaten sekitar 1.835,69 
hektar dan total luas lahan kritisnya 435.405 hektar. Secara rinci dapat dilihat pada pada Tabel 1 berikut ini:

Tabel 1

Luas Wilayah dan Luas Lahan Kritis Di Wilayah DAS Jratun

\begin{tabular}{clcc}
\hline No & Kabupaten & Luas Wilayah (Ha) & Luas Lahan Kritis (Ha) \\
\hline 1 & Brebes & 177.440 & 32,723 \\
2 & Tegal & 98.499 & 15,411 \\
3 & Kota Tegal & 3.735 & 42 \\
4 & Pemalang & 113.919 & 41,813 \\
5 & Pekalongan & 89.297 & 18,102 \\
6 & Kt Pekalongan & 4.678 & 46 \\
7 & Batang & 85.839 & 18,646 \\
8 & Kendal & 101.128 & 28,486 \\
9 & Semarang & 100.886 & 46,095 \\
10 & Kt Semarang & 38.966 & 9.885 \\
11 & Demak & 99.855 & 2.144 \\
12 & Kudus & 44.815 & 12,276 \\
13 & Jepara & 102.520 & 37,649 \\
14 & Pati & 158.209 & 48,956 \\
15 & Rembang & 103.332 & 22,964 \\
16 & Blora & 194.749 & 15,236 \\
17 & Grobogan & 203.016 & 40,955 \\
18 & Boyolali & 109.491 & 43,241 \\
19 & Kota Salatiga & 5.306 & 735 \\
\hline & Jumlah & $\mathbf{1 . 8 3 5 . 6 9}$ & $\mathbf{4 3 5 . 4 0 5}$ \\
\hline
\end{tabular}

Sumber: BPDAS Pemali Jratun (2010).

\section{Penduga Rasio}

Pada pendugaan rata-rata dan total populasi yang didasarkan pada sampel respon pengukuran suatu peubah sebut saja $y_{1}, y_{2}, \ldots, y_{n}$ yang diperoleh melalui penarikan sampel acak sederhana atau acak berlapis (Vincent, 1991). Seringkali terdapat peubah lain yang berkorelasi erat dengan peubah respon $y$, melalui pengukuran peubah $y$ dan satu atau lebih peubah tambahan akan diperoleh tambahan informasi untuk pendugaan nilai rata-rata. Metode pendugaan yang didasarkan pada penggunaan peubah tambahan sebut saja $X$ disebut sebagai pendugaan rasio. Metode ini membutuhkan pengukuran dari dua peubah $y$ dan $X$ pada setiap unit (satuan) dari sampel dan dapat digunakan dengan berbagai jenis penarikan sampel. Dalam kasus ini digunakan pendugaan rasio untuk sampel acak sederhana (Cochran, 1977).

Pendugaan rasio berguna untuk survei-survei tertentu yang bermaksud menduga total populasi tetapi ukuran populasi itu tidak diketahui secara pasti. Dalam kasus ini perlu dilakukan pendugaan terhadap total populasi $\left(Y^{\prime}=N^{*}\right.$ rata-rata $y$; jika $N$ diketahui). Karena $N$ tidak diketahui, dapat digunakan hubungan sebagai berikut (Cochran, 1977): 


$$
\frac{\mu_{y}}{\mu_{x}}=\frac{N \bar{y}}{N \bar{x}}=\frac{\tau_{y}}{\tau_{x}} \text { sehingga } \tau_{y}=\frac{\mu_{y}}{\mu_{x}}\left(\tau_{x}\right)
$$

Nilai $\mu_{\mathrm{y}}$ dan $\mu_{\mathrm{x}}$ dapat diduga oleh rata-rata $y$ dan rata-rata $x$ (nilai rata-rata dari sampel berukuran $n$ ) dan penduga total $y$ dapat ditentukan melalui hubungan sebagai berikut:

$$
\hat{\tau}_{y}=\frac{\bar{y}}{\bar{x}}\left(\tau_{x}\right)=\left(\frac{n \bar{y}}{n \bar{x}}\right)\left(\tau_{x}\right)=\frac{\sum_{i=1}^{n} y_{i}}{\sum_{i=1}^{n} x_{i}}\left(\tau_{x}\right)=\widehat{R}\left(\tau_{x}\right)
$$

di mana

$$
\hat{R}=\frac{\sum_{i=1}^{n} y_{i}}{\sum_{i=1}^{n} x_{i}}
$$

$\hat{R}$ merupakan penduga rasio populasi $\mathrm{R}$ untuk $R=\frac{\mu_{y}}{\mu_{x}}$.

Ragam untuk dugaan nilai rasio sampel adalah $\hat{\operatorname{Var}}(\hat{R})$ yang ditentukan oleh rumus sebagai berikut (Vincent, 1991):

$$
\hat{\operatorname{Var}}(\hat{R})=\left(\frac{N-n}{N}\right)\left(\frac{1}{n \bar{x}^{2}}\right)\left\{\frac{\sum_{i=1}^{n} y_{i}^{2}-2 \hat{R} \sum_{i=1}^{n} x_{i} y_{i}+\hat{R}^{2} \sum x_{i}^{2}}{n-1}\right\}
$$

di mana $(N-n) / N$ merupakan faktor koreksi. Jika $(n / N)$ kecil, faktor koreksi tersebut diabaikan atau dianggap sama dengan satu. Akar pangkat dua dari ragam rasio adalah galat baku dan untuk dugaannya adalah $\mathrm{s}(\hat{R})$.

Dengan menggunakan taraf kepercayaan $(1-\alpha) 100 \%$, batas galat pendugaan nilai rasio dapat ditentukan sebagai berikut:

$$
\text { Batas Galat }(\hat{R})=\operatorname{BG}(\hat{R})=\mathrm{t}_{\alpha / 2 ;(\mathrm{n}-1)} \mathrm{s}(\hat{R})
$$

Dengan pernyataan peluang, galat penduga nilai rasio, $\mathrm{G}(\hat{R})$ dapat ditentukan dengan menggunakan ketentuan sebagai berikut:

$$
\mathrm{P}\{\mathrm{G}(\hat{R})<\mathrm{BG}(\hat{R})\}=1-\alpha
$$

Selang kepercayaan (1- $\alpha) 100 \%$ bagi nilai rasio populasi R, ditentukan sebagai berikut

$$
\mathrm{P}\{\hat{R}-\mathrm{BG}(\hat{R})<\mathrm{R}<\hat{R}+\mathrm{BG}(\hat{R})=1-\alpha
$$

atau $\mathrm{P}\left\{\hat{R}-\mathrm{t}_{\alpha / 2 ;(\mathrm{n}-1)} \mathrm{s}(\hat{R})<\mathrm{R}<\hat{R}+\mathrm{t}_{\alpha / 2 ;(\mathrm{n}-1)} \mathrm{s}(\hat{R})\right\}=1-\alpha$.

Jadi selang kepercayaannya adalah

$$
\hat{R}-\mathrm{t}_{\alpha / 2 ;(\mathrm{n}-1)} \mathrm{s}(\hat{R})<\mathrm{R}<\hat{R}+\mathrm{t}_{\alpha / 2 ;(\mathrm{n}-1)} \mathrm{s}(\hat{R})
$$




\section{HASIL DAN PEMBAHASAN}

Berdasarkan hasil analisis seperti ditunjukkan di atas, secara keseluruhan rasio lahan kritis di wilayah DAS Jratun mencapai $\hat{R}=(435.405 / 1.835,69)=23.72 \%$. Rasio lahan kritis di setiap wilayah berkisar antara $0.98 \%$ untuk Kota Pekalongan (paling rendah) dan $45.69 \%$ untuk Kabupaten Semarang (paling tinggi). Secara rinci urutan rasio lahan kritis untuk setiap kabupaten dapat dilihat dalam Tabel 2 berikut ini.

Tabel 2

Urutan Rasio Lahan Kritis untuk Setiap Kabupaten

\begin{tabular}{lc}
\hline \multicolumn{1}{c}{ Wilayah } & Urutan Rasio (\%) \\
\hline Kota Pekalongan & 0.98 \\
Kota Tegal & 1.13 \\
Demak & 2.15 \\
Blora & 7.82 \\
Kota Salatiga & 13.86 \\
Tegal & 15.65 \\
Brebes & 18.44 \\
Grobogan & 20.17 \\
Pekalongan & 20.27 \\
Batang & 21.72 \\
Rembang & 22.22 \\
Kota Semarang & 25.37 \\
Kudus & 27.39 \\
Kendal & 28.17 \\
Pati & 30.94 \\
Pemalang & 36.7 \\
Jepara & 36.72 \\
Boyolali & 39.49 \\
Semarang & 45.69 \\
\hline
\end{tabular}

Untuk Kabupaten Semarang, Boyolali, Jepara, Pemalang dan Pati, rasio di atas $30 \%$, sehingga perlu perhatian secara serius dalam menanggulangi kondisi lahan yang ada di wilayahnya agar tidak terjadi hal-hal yang tidak diinginkan.

Jika diinginkan untuk melakukan pendugaan selang dari pendugaan rasio dalam sampling, berikut ini hanya sebagai gambaran penerapan penduga selang dalam rasio sampling (karena dalam kasus ini cukup dilakukan pendugaan rasionya saja). Di atas telah ditentukan penduga nilai rasio $\hat{R}=$ $(435.405 / 1.835,69)=23.72 \%$. Selanjutnya, penduga selang untuk rasio lahan kritis ditentukan dengan menggunakan ketentuan yang terdapat dalam metode penelitian yang terlebih dulu harus ditentukan ragam atau simpangan baku untuk ukuran rasio tersebut. Dari data luas wilayah dan luas lahan kritis untuk setiap kabupaten di atas diperoleh ragam rasio 0,298886572 dan nilai dugaan galat baku rasio adalah $\mathrm{s}(\hat{R})=0,546705197$. Dengan menggunakan taraf kepercayaan (1-0.05)100\%, dari tabel $t$ diperoleh nilai $\mathrm{t}_{0.05 / 2 ;(19-1)}=2.10$ dan batas galat pendugaan nilai rasio dapat ditentukan sebagai berikut: 
Batas Galat $(\hat{R})=\operatorname{BG}(\hat{R})=\mathrm{t}_{\alpha / 2 ;(\mathrm{n}-1)} \mathrm{s}(\hat{R})=2.10 * 0,128859651=0,270605266$

Batas atas selang kepercayaan (1- 0.05) $100 \%$ bagi nilai rasio populasi $\mathrm{R}$ dapat ditentukan sebagai berikut

$$
\mathrm{P}\left\{\mathrm { R } < 0 , 2 3 7 2 + \mathrm { BG } ( \hat { R } ) = 0 . 9 7 5 \text { atau } \mathrm { P } \left\{\mathrm{R}<0,2372+\mathrm{t}_{\alpha / 2 ;(\mathrm{n}-1)} \mathrm{s}(\hat{R})=0,975\right.\right.
$$

Batas atas selang kepercayaan untuk penduga nilai rasio adalah

$$
\mathrm{R}<0,507805266
$$

Artinya rasio lahan kritis terhadap total luas keseluruhan untuk daerah aliran sungai Jratun masih di bawah $50,78 \%$.

\section{PENUTUP}

Berdasarkan hasil kajian di atas dapat ditarik beberapa kesimpulan sebagai berikut: (1) Kerusakan lahan yang diakibatkan oleh berbagai faktor dapat menimbulkan lahan kritis, ini berpeluang besar untuk kondisi Indonesia yang merupakan negara beriklim tropis dengan intensitas curah hujan yang tinggi setiap tahun, sehingga potensial menimbulkan daya merusak lahan; (2) Berdasarkan data dan hasil kajian di 19 Kabupaten, rasio lahan kritis terhadap total luas keseluruhan untuk daerah aliran sungai Jratun adalah $23,72 \%$. Artinya untuk Kabupaten yang nilai rasionya cukup besar perlu perhatian secara serius dalam menanggulangi kondisi lahan yang ada di wilayahnya. Dari urutannya, yang paling besar adalah Kabupaten Semarang dan berturut-turut Kabupaten Boyolali, Jepara, Pemalang, dan Pati yang mencapai di atas $30 \%$.

\section{DAFTAR PUSTAKA}

BPDAS Pemali Jratun. (2010). Review Lahan Kritis Tahun 2009. Diakses dari http://www.bpdaspemalijratun.net/index.php?option=com_content\&view=article\&id=10:lahankritis\&catid $=4$ : evaluasi\&Itemid $=46$.

Cochran, W. G. (1977). Sampling Techniques ( $3^{\text {rd }}$ ed.). New York: John Wiley and Sons.

Douglas, Montgomery C. \& William, Hines W. (1990). Probabilita dan Statistik dalam Ilmu Rekayasa dan Manajemen (edisi ke-2). Jakarta: UI-Press.

Vincent, Gaspersz (1989). Statistika. Bandung: Tarsito.

Vincent, Gaspersz. (1991). Teknik Penarikan Contoh untuk Penelitian Survei. Bandung: Tarsito. 